\title{
Binary mixture micellar systems of F127 and P123 for griseofulvin solubilisation
}

\author{
Lillian Maria Uchôa Dutra ${ }^{1 *}$, Maria Elenir Nobre Pinho Ribeiro', Igor Marques Cavalcante', \\ Débora Hellen Almeida de Brito ${ }^{1}$, Luana de Moraes Semião', Raquel Freitas da Silva ${ }^{1}$,
} Pierre Basílio Almeida Fechine ${ }^{2}$, Stephen George Yeates ${ }^{3}$ and Nágila Maria Pontes Silva Ricardo ${ }^{1}$

\author{
${ }^{1}$ Laboratory of Polymers and Materials Innovation, Department of Organic and Inorganic Chemistry, \\ Universidade Federal do Ceará - UFC, Fortaleza, CE, Brazil \\ ${ }^{2}$ Group Chemistry of Advanced Materials, Departament of Physical, Chemical and Analytic Chemistry, \\ Universidade Federal do Ceará - UFC, Fortaleza, CE, Brazil \\ ${ }^{3}$ Organic Materials Innovation Centre, School of Pharmacy and Pharmaceutical Sciences, \\ University of Manchester, Manchester M13 9PL, United Kingdom \\ *Imudutra@hotmail.com
}

\begin{abstract}
Pluronics ${ }^{\circledR}$ molecules self-assemble in aqueous solution providing a core/shell architecture that improves the solubility of hydrophobic drugs. Binary mixtures of Pluronics ${ }^{\circledR}$ have been studied as drug nanocarriers in order to combine their advantages, like high colloidal stability, small particle size and good solubilisation capacity $\left(\mathrm{S}_{\mathrm{cp}}\right)$. In this work we studied Pluronics ${ }^{\circledR}$ binary mixture, P123 and F127, as nanocarriers of the hydrophobic drug griseofulvin. P123 $\left(\mathrm{E}_{21} \mathrm{P}_{67} \mathrm{E}_{21}\right)$ shows a relative good $\mathrm{S}_{\mathrm{cp}}$, whereas $\mathrm{F} 127\left(\mathrm{E}_{98} \mathrm{P}_{67} \mathrm{E}_{98}\right)$ shows a good colloidal stability. According to data, these binary mixtures form stables nano-sized comicelles in aqueous solution. The $\mathrm{S}_{\mathrm{cp}}$ of the P123/F127 systems at 25 and $37^{\circ} \mathrm{C}$ was monitored by UV/Visible spectroscopy, showing good results at both temperatures, as would be expected, since P123/F127 have similar length hydrophobic block. Hydrophobic-dependence and temperature-responsive of the systems were evaluated by CMC, particle size and colloidal stability. Hence, stables P123/F127 comicelles may have potencial as hydrophobic drug delivery.
\end{abstract}

Keywords: binary mixtures, griseofulvin, Pluronics.

\section{Introduction}

The use of block copolymers in pharmaceutical science and industry has a long history. In this context, self-assembly copolymer surfactants have been used as solubilizing and stabilizing agents of poorly water soluble drugs in pharmaceutical formulations ${ }^{[1-5]}$. These polymers form micelles in aqueous solution with a core/shell architecture, where the hydrophobic core is segregated from the aqueous exterior by a hydrophilic shell, which provide themselves an effective drug carrier ${ }^{[3,6-9]}$.

Among these systems, amphiphilic triblock copolymers formed by poly(ethylene oxide) (E) and poly(propylene oxide) (P) blocks with an $\mathrm{E}_{M} \mathrm{P}_{N} \mathrm{E}_{M}$ arrangement (where " $m$ " and " $n$ " denote the monomers units) have been studied. They are known as Pluronics ${ }^{\circledR}$, and have been investigated due to several reasons. In aqueous solution their amphiphilic molecules self-assemble in micelles, where $\mathrm{P}$ segments comprise a hydrophobic core as a nanoenvironment for the incorporation of hydrophobic drugs, which may increase the drug stability. Their hydrophilic block E, forming the corona, prevents aggregation, protein adsorption and recognition by the reticulo endothelial system (RES) that increases their blood time circulation ${ }^{[5,7,9]}$. These copolymers in aqueous solution form micelles or physical gels, and this behavior will be dependenton their concentration and temperature in the system. At concentrations above the critical micelle concentration (CMC) and at temperatures above the critical micelle temperature (CMT), the block copolymer molecules can self-assemble into micelles in aqueous solutions. At higher concentrations, the closed packing of micelles results in the formation of gel-like ordered structures. Thus, Pluronics ${ }^{\circledR}$ solutions are capable of exhibiting thermally reversible gelation behavior $^{[4,10,11]}$.

These micelles can show spherical, cylindrical or lamellar morphology. This depends on the relative length of both blocks, which changes the hydrophilic-lipophilic balance (HLB) of block copolymers ${ }^{[7,8,10,11]}$. Due to their small particle size $(<100 \mathrm{~nm})$ these systems exhibit many advantages such as targeting ability, long circulation time and easy production on effective delivery of drugs. Incorporation of low molecular mass drugs into Pluronic ${ }^{\circledR}$ micelles can increase their solubility and stability and improve their pharmacokinetics and biodistribution ${ }^{[7-9,11-13]}$.

Lee et al. ${ }^{[8]}$ reported that some binary mixtures of Pluronics ${ }^{\circledR}$ like L121/F127 show cooperative aggregation, however, these kind of systems need extra energy input such as heating and ultrasonication to form stable nano-sized particles. Therewith, Lee et al. ${ }^{[8]}$ studied binary mixtures with similar length of hydrophobic block which these $\mathrm{E}_{M} \mathrm{P}_{N} \mathrm{E}_{M}$ copolymers are chosen as nanocarriers for encapsulation of hydrophobic drugs in order to combine the advantages in their physicochemical properties such as a high colloidal 
stability, formation of small particle size, good solubilisation capacity and thermally reversible gelation behavior ${ }^{[8,10,11]}$.

In this study we have focused on the solubilisation capacity $\left(S_{C P}\right)$ between Pluronics ${ }^{\circledR}$ with similar length of hydrophobic block, P123 $\left(\mathrm{E}_{21} \mathrm{P}_{67} \mathrm{E}_{21}\right)$ and F127 $\left(\mathrm{E}_{98} \mathrm{P}_{67} \mathrm{E}_{98}\right)$, by the usual quantification technique ofUV/Visible spectroscopy ${ }^{[1,14,15]}$. Although the hydrophobic griseofulvin was used as a standard drug to compare the values of $S_{C P}$ of the copolymers and their mixture, recently, griseofulvin has been attracting considerable interest as a potential anticancer drug, that shows low toxicity and efficacy to kill cancer cells ${ }^{[6,8,16,17]}$. In addition, studies such as micellar properties, i.e., critical micelle concentration (CMC) and particle size as micelle hydrodynamic diameter $\left(D_{H}\right)$, are necessaries to confirm their values of $S_{C P}$, and verified their stability as hydrophobic drug deliveries at body temperature ${ }^{[1,10,11,13,18]}$.

\section{Materials and Methods}

\subsection{Materials}

The copolymers $\mathrm{E}_{98} \mathrm{P}_{67} \mathrm{E}_{98}(\mathrm{~F} 127)$ and $\mathrm{E}_{21} \mathrm{P}_{67} \mathrm{E}_{21}(\mathrm{P} 123)$ ( $\mathrm{E}=$ ethylene oxide and $\mathrm{P}=$ propylene oxide), commercially available as Pluronics ${ }^{\circledR}$ (Figure 1a), were purchased from BASF but supplied by Uniquema and used as received. Values of molecular characteristics were measured by gel permeation chromatography (GPC) using N, N-dimethylacetamide as solvent $70^{\circ} \mathrm{C}$, and these results were published in a previous study by Chaibundit et al. ${ }^{[1]}$ (Table 1). The fluorescent dye, DPH (1,6-diphenyl-1,3,5-hexatriene), was supplied by

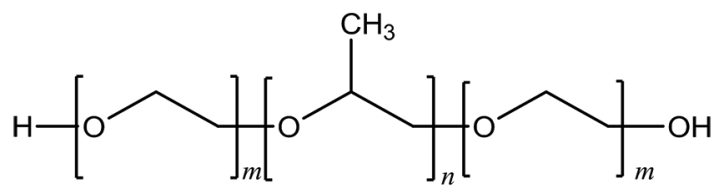

(a)

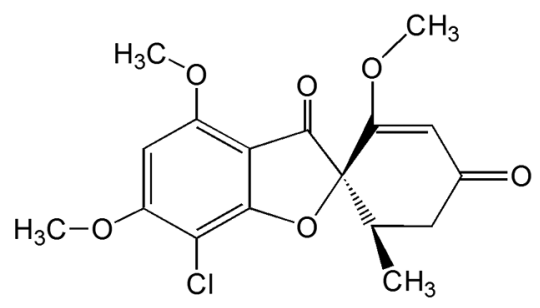

(b)

Figure 1. (a) Chemical structure of $\mathrm{E}_{M} \mathrm{P}_{N} \mathrm{E}_{M}$ and; (b) Chemical structure of griseofulvin.

Table 1. Molecular characteristics of the copolymers P123 $\left(\mathrm{E}_{21} \mathrm{P}_{67} \mathrm{E}_{21}\right)$ and $\mathrm{F} 127\left(\mathrm{E}_{98} \mathrm{P}_{67} \mathrm{E}_{98}\right)$, data published by Chaibunditetal ${ }^{[11]}$ and $\mathrm{Oh}$ et al. ${ }^{[13]}$.

\begin{tabular}{cccccc}
\hline Copolymer & $\begin{array}{c}\boldsymbol{M}_{n}^{\mathrm{a}} \\
\left(\mathrm{g} \mathrm{mol}^{-1}\right)\end{array}$ & $\boldsymbol{\%} \boldsymbol{E}^{\mathrm{b}}$ & $\boldsymbol{M}_{w} \boldsymbol{M}_{\boldsymbol{n}}$ & $\begin{array}{c}\boldsymbol{M}_{w}^{\mathrm{c}} \\
\left(\mathbf{g ~ m o l}^{-1}\right)\end{array}$ & $\mathbf{H L B}^{\mathrm{d}}$ \\
\hline $\mathrm{E}_{21} \mathrm{P}_{67} \mathrm{E}_{21}$ & 5.75 & 32 & 1.10 & 6.6 & 8 \\
$\mathrm{E}_{98} \mathrm{P}_{67} \mathrm{E}_{98}$ & 12.5 & 69 & 1.20 & 15 & 22 \\
\hline
\end{tabular}

${ }^{\text {a} A v e r a g e ~ m o l e c u l a r ~ w e i g h t ~}{ }^{[11]}$. ${ }^{b}$ Hydrophilic portion of copolymer ${ }^{[1]]}$. ${ }^{\mathrm{c} N u m b e r}$ average molecular weight, calculeted from Mnand $\mathrm{Mw} / \mathrm{Mn}^{[11]}$. ${ }^{\mathrm{H}}$ Hydrophilic-lipophilic balance ${ }^{[13]}$.
Biochemika, and griseofulvin (weight average of $352,8 \mathrm{~g} \mathrm{~mol}^{-1}$, Figure 1b) was supplied by Sigma-Aldrich (Poole Dorset, UK). All the other materials used were of analytical grade.

\subsection{Binary mixtures}

Pluronics ${ }^{\circledR} \mathrm{P} 123$ and F127 mixed systems were prepared by two distinct methods: polymer/solution w/w and w/v. For the solubilisation and size particle procedures each mixture was prepared weighing the copolymers and dissolving them in Milli-Q ${ }^{\circledR}$ water to the desired concentration of $1 \%$ $(\mathrm{w} / \mathrm{w})$, where the weight percentages of P123 in the mixture were 30,50 and $70 \%$, and, in what follows, the mixtures are referred to as PF 30, PF 50 and PF 70. In the critical micelle concentration experiment, stock solutions of the binary mixtures PF 30, PF 50 and PF 70 (1\%, w/v) were prepared by dissolving the copolymers in Milli- $\mathrm{Q}^{\circledR}$, allowed to stir for at least $14 \mathrm{~h}$, and then stored at $4{ }^{\circ} \mathrm{C}$ overnight. The solutions were transferred to room temperature $\left(25^{\circ} \mathrm{C}\right)$ and kept for more than $1 \mathrm{~h}$ before further dilutions.

\subsection{Critical micelle concentration (CMC)}

Various methods are used to determine the CMC of surfactants. These methods (e.g. dye solubilisation and surface tension) measure properties that show an abrupt change when the surfactant molecules begin to micellize as its concentration changes. As the surfactant concentration increases and it begins to micellize, the hydrophobic dye starts to migrate from the polar aqueous medium into the unpolar core of the micelles. In this hydrophobic environment, the intensity of the dye absorbance increases abruptly. The determination of CMC of the copolymers and their mixtures was performed through the method of dye solubilisation, using a Hitachi Spectrophotometer U-2000. The hydrophobic dye 1,6-diphenyl-1,3,5-hexatriene (DPH) was used as a probe to determine micelles formation. DPH was dissolved in methanol $(0.4 \mathrm{mM})$ in the dark, and added to the solutions of the copolymers in the ratio of $1: 100(30 \mu \mathrm{L}$ $\mathrm{DPH}: 3 \mathrm{ml}$ solution). Thus, solutions of copolymers (ranging from $0.0001-1 \%$ ) in methanol and $0.004 \mathrm{mM}$ DPH were obtained. The absorbance wavelength used for the DPH was $356 \mathrm{~nm}$. The absorbance measurements of the samples were taken around 3 and $24 \mathrm{~h}$ after the addition of DPH. During all the process the solutions containing DPH were kept in the dark. These studies were performed at 25 and $37^{\circ} \mathrm{C}$. Plots of absorbance against $\log \mathrm{C}$ (wt. \%) were used to determine the onset of micellization ${ }^{[10]}$.

\subsection{Solubilisation}

The method used for the solubilisation of griseofulvinwas the "shake flask" method, adapted from Aliabadi and Lavasanifar ${ }^{[15]}$. Copolymers and their mixtures were dissolved in Milli-Q ${ }^{\circledR}$ water $(1 \% \mathrm{w} / \mathrm{w})$. Then, a portion of $\operatorname{drug}(\mathrm{w} \approx 10 \mathrm{mg}$ ) was added to an aliquot of copolymer solution $(10 \mathrm{~mL})$. The system was slowly stirred at $25^{\circ} \mathrm{C}$ $\left( \pm 0.1^{\circ} \mathrm{C}\right)$ for 4 days in a thermostatic bath. After that, $3 \mathrm{~mL}$ of supernatant were filtered $(0.45 \mu \mathrm{m}$ Millipore $)$ to remove any non-solubilized drug. Aliquots of the filtered samples were diluted with methanol (10x) and the drug concentration was monitored by UV/Visible spectroscopy at $292 \mathrm{~nm}$, using a calibration curve based on Beer's law. 
For more 4 days, the remaining supernatant $(7 \mathrm{~mL})$ was stirred at $37{ }^{\circ} \mathrm{C}\left( \pm 0.1{ }^{\circ} \mathrm{C}\right)$, and then, the same procedure was performed. All measurements were made in triplicate.

\subsection{Micelle size}

DLS technique is based on the Brownian motion, where the time-dependent fluctuations in the intensity of scattered light from a suspension of particles undergoing random. Analysis of these intensity fluctuations allows for obtain the diffusion coefficients, and by aid of Stokes- Einstein equation can determine the particle size, i.e., hydrodynamic diameter or radius $\left(D_{H}\right.$ or $\left.r_{H}\right)$. Using the equipment Nano Zetasizer, Malvern Zetasizer Nano ZS (ZEN 3500) the $D_{H}$ of triblock copolymers P123, F127 and their mixtures PF 30,50 and 70 , with and without drug, were determined at 25 and $37^{\circ} \mathrm{C}$. The measurements were made using the filtered aliquots from the solubilisation procedure. The systems were investigated using 30 scans with $30 \mathrm{~s}$ acquisition time allowed for each scan. All the measurements were made in triplicate ${ }^{[11,18]}$.

\section{Results and Discussion}

\subsection{Critical micelle concentration (CMC)}

The $\mathrm{CMC}$, the fraction of molecules in micellar form, and the size and the aggregation number of the micelles, as well as the temperature dependence of these parameters, are of great interest for aqueous $\mathrm{E}_{M} \mathrm{P}_{N} \mathrm{E}_{M}$ block copolymer micellar solutions. As observed by Alexandridis et al. ${ }^{[10]}$, it becomes necessary to study the systematic formation of the micelles of these block copolymers, determining the micellization origin and the effects of hydrophilic (E) and hydrophobic $(\mathrm{P})$ block in this parameter ${ }^{[10]}$. DPH solubilisation method, using UV/Visible spectroscopy, was performed by Alexandridis et al. ${ }^{[10]}$ to study the micellization of different Pluronics ${ }^{\circledR}$ indicated that the optimum wavelength of DPH absorbance is $356 \mathrm{~nm}^{[10]}$. The CMC can be determined from the plots of DPH absorbance versus $\log \mathrm{C}$ (wt. \%): the concentration where an abrupt increase of absorbance occurs is the CMC (Figure 2a).

Micelle formation of P123, F127 and their mixtures in aqueous solutions was monitored by UV/Visible using DPH as a dye probe. The $\mathrm{CMC}$ values were determined at $25^{\circ} \mathrm{C}$, once this is the temperature of preparation and storage of some commercial drug formulations, and at $37^{\circ} \mathrm{C}$, the body temperature. Copolymers used as solubilizing agents should be mostly micellized in dilute aqueous solution. Low CMC values of surfactants are interesting for drug solubilisation because they provide high stability of their micelles in solutions upon dilution in the blood ${ }^{[7,12,18,19]}$.

Figure 2b shows CMC values of P123, F127 and their mixtures at 25 and $37{ }^{\circ} \mathrm{C}$. The results were expressed as weight percentage of polymer in solution (wt. \%), since this is the usual way to evaluate the efficiency of surfactants for commercial applications ${ }^{[18]}$. According to Tadros ${ }^{[20]}$, temperature acts differently on the solubility of the different types of surfactants. It was observed that those surfactants that have altered solubility with increasing temperature would have the same behavior in relation to their $\mathrm{CMC}$, since the surfactant solubility interferes in their CMC.

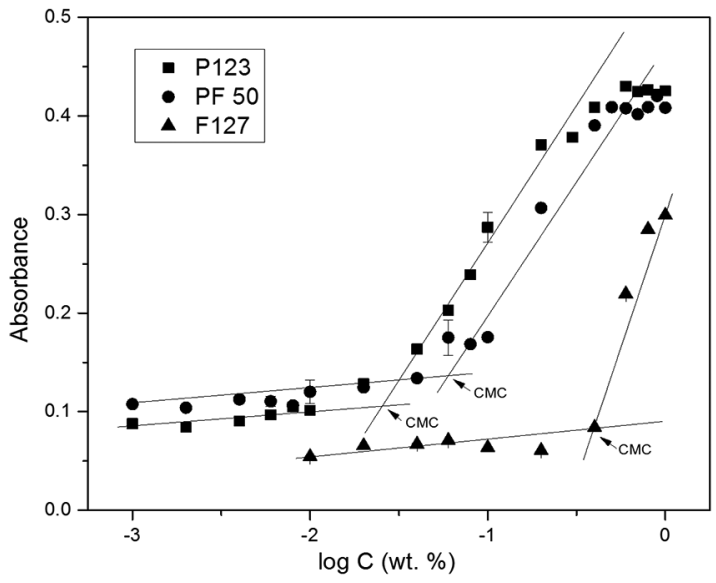

(a)

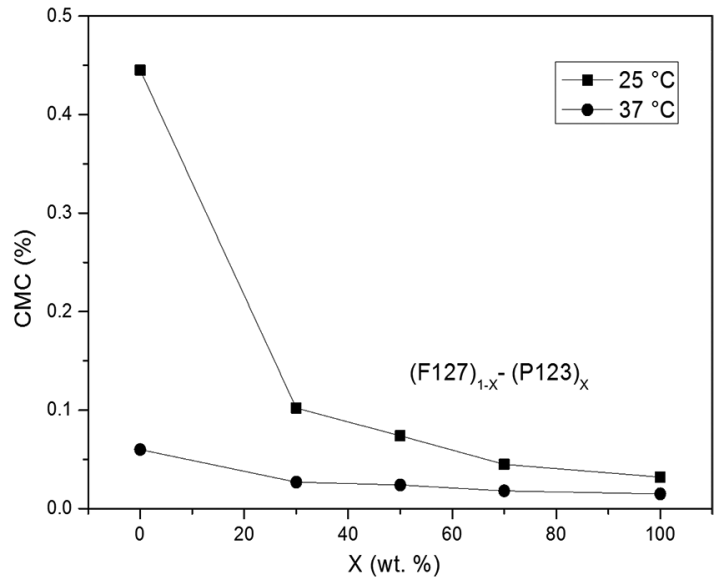

(b)

Figure 2. (a) Plots of absorbance of DPH versus $\log \mathrm{C}$ (wt. \%) of P123, F127 and the mixture PF 50 at $25{ }^{\circ} \mathrm{C}$; (b) Effect of temperature at CMC of copolymers P123, F127 and their mixtures, PF 30, 50 and 70.

In general, the $\mathrm{CMC}$ of nonionic copolymers undergoes reduction as the temperature increase ${ }^{[10]}$. Increasing temperature decreases the $\mathrm{CMC}$, in which the polymer becomes more hydrophobic due to micellar growth, and this effects on the polarity of the polymer decreases, as the temperature rises up, due to the dehydration of the E chains ${ }^{[1,21]}$.The CMCs of all systems studied in this work at $37^{\circ} \mathrm{C}$ are lower than at $25^{\circ} \mathrm{C}$ (Figure $2 \mathrm{~b}$ ), consistent with the studies reported by Tadros ${ }^{[20]}$ for nonionic surfactants and by Alexandridis et al. ${ }^{[10]}$ for $\mathrm{E}_{M} \mathrm{P}_{N} \mathrm{E}_{M}$ block copolymers ${ }^{[10,20]}$.

Attwood et al. ${ }^{[18]}$ reported that, within a series of Pluronics $^{\circledR}, \mathrm{CMC}$ values are affected by variation of E-block length. Although the effect of poly(ethylene oxide) (E) on the $\mathrm{CMC}$ is less pronounced than that of poly(propylene oxide) (P), the $\mathrm{E}_{M} \mathrm{P}_{N} \mathrm{E}_{M} \mathrm{CMC}$ becomes dependent of the number of $\mathrm{E}$ units when two copolymers have the same hydrophobic block length. This would indicate that the micelle formation becomes more difficult than more hydrophilic the molecules ${ }^{[10,18]}$. The higher is the hydrophobic character of the copolymer the lower will be its CMC, since micellization reduces its unfavorable interactions with water. 
Hence, the results obtained in this work to the copolymers $\mathrm{P} 123$ and $\mathrm{F} 127$ were 0.055 and $0.357 \mathrm{mM}$ at $25^{\circ} \mathrm{C}$, and 0.006 and $0.048 \mathrm{mM}$ at $37^{\circ} \mathrm{C}$, respectively, consistent with the values published by Alexandrids et al. ${ }^{[9]}$ and Attwood and Booth $^{[22]}$. Thus, we can observe that the CMC of F127 is higher than that of $\mathrm{P} 123$, once the hydrophilic block (E) of F127 is five times larger than that of $\mathrm{P} 123^{[18]}$

The mixtures kept the profile of the temperature dependence of the copolymers alone (Figure 2b). The CMC values for the mixtures at 25 and $37^{\circ} \mathrm{C}$ were found to be intermediate compared to those found for the pure copolymers. We could observe that as $\mathrm{P} 123$ ratio in the mixtures increases, CMC decreases, once P123 has a lower $\mathrm{CMC}$ than F127. For example, the CMC value found for PF 30 was 0.027 wt. \%, while for PF 70 was 0.018 wt. $\%$ at $37^{\circ} \mathrm{C}$. The low $\mathrm{CMC}$ values of these systems at $37^{\circ} \mathrm{C}$ bring to these mixtures promising pharmacological applications once the micelles could remain stable even upon dilution in the blood $^{[7,8,11,13,15,18,23]}$.

\subsection{Micelle size}

Generally, so that the efficiency of the encapsulated active be long during its circulation in blood, the micelles should be small enough to evade detection and destruction by the reticular endothelial system ${ }^{[12]}$.

In studies by Chaibundit et al. ${ }^{[11]}$ it was observed that binary mixtures of Pluronics ${ }^{\circledR}$, which have the same hydrophobic block length, formed stables comicelles in diluted aqueous solution, and these mixtures showed a single narrow distribution and small particles at room and body temperature ${ }^{[10,11]}$. In studies by Wei et al. ${ }^{[12]}$ this behavior was observed for the mixtures between P123 and F127 solubilizing the drug Paclitaxel. These micelles showed hydrodynamic diameter $\left(D_{H}\right)$ ranging from 20 to $30 \mathrm{~nm}$ and polydispersivity index between 0.14 and 0.23 .

In our study, P123/F127 micelles showed unimodal size distribution and average micelle size, proving comicelles formation to the same mixtures loading griseofulvin drug. $D_{H}$ values of the systems F127, P123 and their mixtures PF 30, 50 and 70, without (Figure 3a) and with (Figure 3b) griseofulvin, at 25 and $37^{\circ} \mathrm{C}$ are shown in Figure 3 . The $D_{H}$ of copolymer F127 is larger than that of P123, since F127 has a hydrophilic chain length of poly(oxyethylene) bigger than P123.

The encapsulated drug, griseofulvin, had virtually no influence on the hydrodynamic radius $\left(r_{H}\right)$ of micelles of P123 and F127, considering the standard deviation of the analyses (Figure 4). However, this increase might nevertheless reflects a certain increase in the hydrophobic micelle core size because of griseofulvin solubilisation ${ }^{[12]}$.

The difference of $r_{H}$ for the systems P123 and F127, with and without encapsulated drug, is between 1 and $3 \mathrm{~nm}$, and for their mixtures this difference is even smaller, as seen by Wei et al. ${ }^{[12]}$. Therefore, micelles of binary mixtures of Pluronics ${ }^{\circledR}$ form particles smaller than $200 \mathrm{~nm}$, which is a great advantage for use in pharmacological applications ${ }^{[8,12]}$.

\subsection{Solubilisation}

We have appointed important characteristics to be sought in a micellar system for drug delivery, such as small micelle size and a low $\mathrm{CMC}$, giving a high extent of micellization and stability and high solubilisation capacity $\left(S_{C P}\right)$.The encapsulation efficiency can be measured by compatibility of the micelle core with the drug, and this

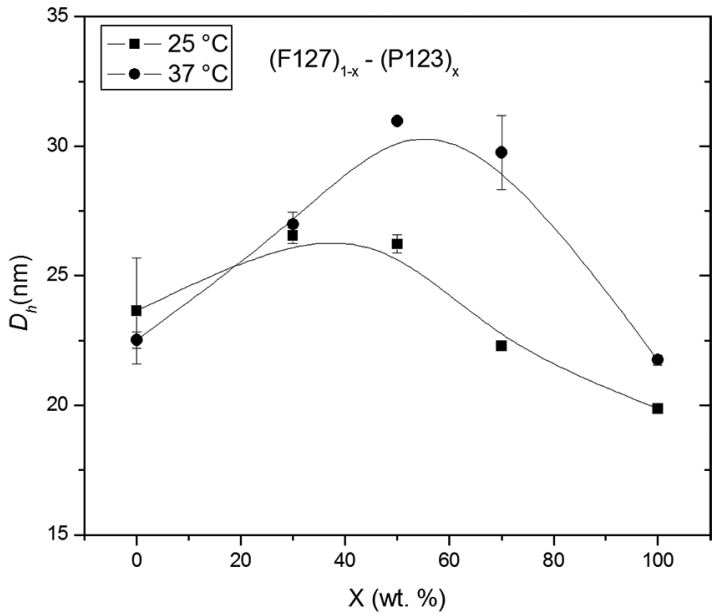

(a)

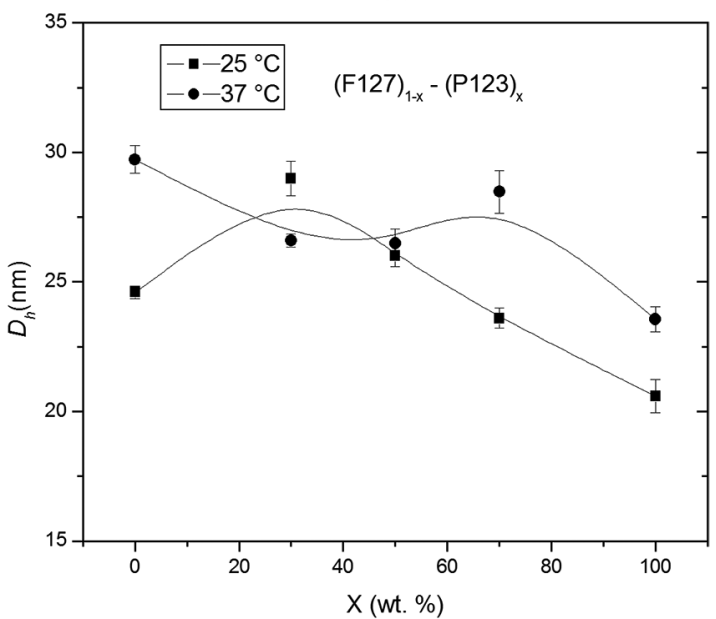

(b)

Figure 3. Hydrodynamic diameter $\left(D_{H}\right)$ of copolymers systems at $1 \% \mathrm{w} / \mathrm{v}$ at 25 and $37^{\circ} \mathrm{C}$ : (a) without griseofulvin; and (b) with griseofulvin.

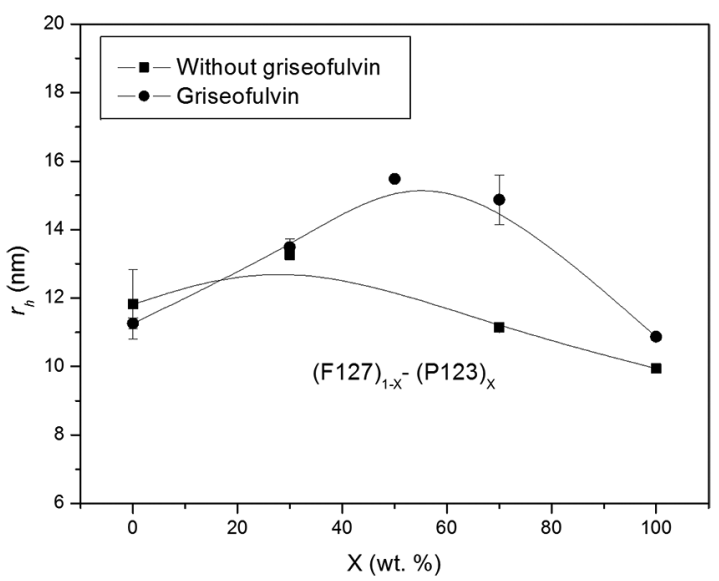

Figure 4. Effect of encapsulated drug on $r_{H}$ of the systems at $25^{\circ} \mathrm{C}$. 
interaction controls the rate of uptake and release of the $\operatorname{active}^{[5,22]}$

Values of $S_{C P}$ of the copolymer solutions for griseofulvin were obtained by UV/Visible spectroscopy, and these results are reported in milligrams of solubilized drug per gram of copolymer in solution $\left(S \mathrm{mg} \cdot \mathrm{g}^{-1}\right)$, after correction for the solubility of griseofulvin in water $\left(S_{0} \mathrm{mg} \cdot \mathrm{dL}^{-1}\right)$, $S_{C P}=S-S_{0}[6,14,22,24]$. The values of $S_{0}$ for griseofulvin were 1.34 and $1.83 \mathrm{mg} \cdot \mathrm{dL}^{-1}$ at 25 and $37^{\circ} \mathrm{C}$, respectively, similar to those reported by Ribeiro et al. ${ }^{[24]}$, and the values of $S_{C P}$ (mg/g) obtained for F127, P123 and their mixtures, PF 30, 50 and 70, are showed in Figure 5.

Bearing in mind earlier studies by Attwood and Booth ${ }^{[22]}$ and Crothers et al. ${ }^{[1]}$, we have used griseofulvin as a standard aromatic drug for comparing the $S_{C P}$ of micellar solutions of different block copolymers. Solubilisation capacity data published by Attwood and Booth ${ }^{[22]}$ to P123 and F127, 3.0 and $2.2 \mathrm{mg} \mathrm{g}^{-1}$, were similar with our results, considering the standard deviation of samples, using the same method and temperature ${ }^{[22]}$.

As it would be expected from this discussion, the solubilisation capacity of $\mathrm{E}_{M} \mathrm{P}_{N} \mathrm{E}_{M}$ diluted solutions, with hydrophobic P blocks, showed low values when compared with values of other types of copoly(oxyalkylenes) ${ }^{[1,22,24]}$. However, Lee et al. ${ }^{[8]}$ studied the $S_{C P}$ and aqueous stability of copolymers of $\mathrm{E}_{M} \mathrm{P}_{N} \mathrm{E}_{M}$ type, analyzing their HLB (hydrophilic/lipophilic balance), and observed that the solubility of the drug in these nano-colloidal systems do not just depend on hydrophobicity of the block, but also on the length of the hydrophilic block ${ }^{[8]}$. We observed that our $S_{C P}$ value of P123 was higher than that of F127: 3.5 and $1.5 \mathrm{mg} / \mathrm{g}$ at $25^{\circ} \mathrm{C}$, respectively (Figure 5). According to Jindal and Mehta ${ }^{[5]}$, the HLB values for the copolymers P123 and F127 are 8 and 22, respectively, which the higher the HLB, the higher hydrophilicity, and these balance values are an indicative that the encapsulation efficiency of P123 for hydrophobic drugs would be better than that of F12 $7^{[5,21]}$.

Lee et al ${ }^{[8]}$ studied the direct effect of the hydrophiliclipophilic balance in the kinetic and thermodynamic stability of micelles in binary mixtures of Pluronics ${ }^{\circledR}$. In their studies the L121 (HLB = 2) showed less aqueous stability and previous precipitation at diluted solutions, when added hydrophilic triblocks $\mathrm{E}_{M} \mathrm{P}_{N} \mathrm{E}_{M}$ with the same hydrophobic $\mathrm{P}$ portion and with long hydrophilic chain, was observed an increase on aqueous stability.

According to Lee et al. ${ }^{[8]} \mathrm{P} 123$ with a low CMC increased the thermodynamic stability due to tight hydrophobic interactions with hydrophobic blocks, while the Pluronic ${ }^{\circledR}$ with long hydrophilic chain, like F127, increased kinetic stability due to steric hindrance for micelle aggregation ${ }^{[8]}$. These results suggest that Pluronics ${ }^{\circledR}$ with relatively low HLB increase the thermodynamic stability, but do not affect the kinetic stability. This way, incorporating long PEO chains into micelles to prevent secondary micellar aggregation by steric hindrance, forming a kinetically stable dispersion ${ }^{[8]}$.

The mixing of P123 and F127 is studied in this work to overcome the limitations of low solubilisation capacity and combine the advantages of high stability of Pluronics ${ }^{\circledR}$. Further analyzing our values of $S_{C P}$ for griseofulvin in the binary mixtures, PF 30, 50 and 70, we observed that increasing
P123 levels in PF mixtures increase the solubilisation of griseofulvin.

These results were expected, as discussed by Lee et al. ${ }^{[8]}$ and Kulthe et al. ${ }^{[19]}$, which the Pluronics ${ }^{\circledR}$ mixtures are good solubilising agents of hydrophobic drugs, where the increase in the encapsulated efficiency by the micelles it was observed for mixtures which had a higher ratio of hydrophobic polymer. Supporting our values of $S_{C P}$ to PF mixtures where this behavior still keep the high solubilisation capacity to mixtures that have higher rates of $\mathrm{P} 123^{[8,19,21]}$.

In studies with a series of $\mathrm{E}_{M} \mathrm{P}_{N} \mathrm{E}_{M}$ copolymers was observed the influence of temperature on solubilisation capacity ${ }^{[21]}$. In our studies, $S_{C P}$ at $25^{\circ} \mathrm{C}$ is lower than at $37^{\circ} \mathrm{C}$ (see Figure 5). According to Kadam et al. ${ }^{[21]}$, this behavior can be explained by the increase in thermal vibrations of the monomers in the micelles, resulting in an increase in the space available for solubilisation of the drug into the micelle, in addition to the increased griseofulvin solubility in water, varying for high temperature ${ }^{[1,21]}$.

This increase in $S_{C P}$ with the increase of temperature can be better understood through the micelle-water partition coefficient, calculated by a thermodynamic point of view. The solubilisation can be considered as a normal partitioning of the drug between micelle and aqueous phases and the partition coefficient is the ratio of the drug concentration in the micelle to that in water for a particular surfactant concentration $\left(P=S_{C P} / S_{O}\right)$. The standard free energy of solubilisation is $\Delta \mathrm{G}_{S}^{\circ}=-\mathrm{RT} \ln P$, where $\mathrm{R}$ is the universal gas constant, $\mathrm{T}$ is the temperature in Kelvin scale, and $P$ is the partition coefficient between the micelle and the aqueous phase $^{[6]}$. Table 2 shows the influence of temperature on the partition coefficient of griseofulvin.

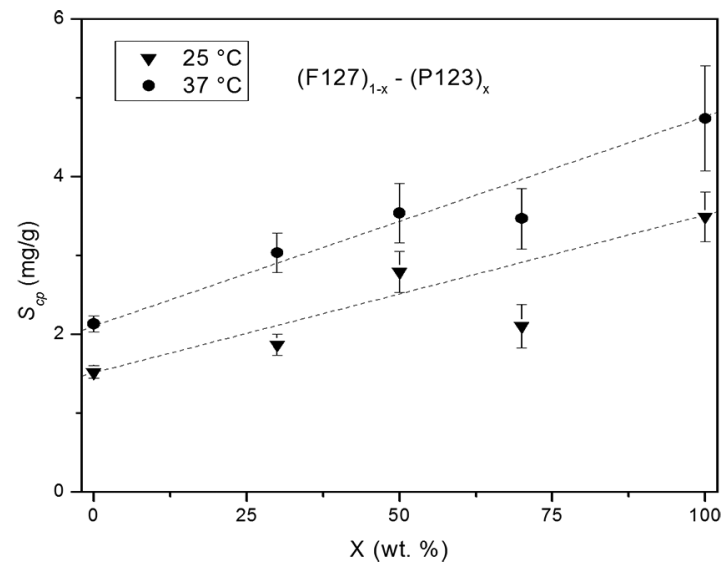

Figure 5. Solubilisation capacity $\left(S_{C P}\right)$ of griseofulvin in $1 \mathrm{wt}$ \% solutions of P123, F127 and their binary mixtures, PF 30, 50 and 70 , at 25 and $37^{\circ} \mathrm{C}$.

Table 2. Partition coefficient and Gibbs free energy at 25 and $37^{\circ} \mathrm{C}$ for all the systems.

\begin{tabular}{ccccc}
\hline \multirow{2}{*}{ Systems } & \multicolumn{2}{c}{$\mathbf{2 5}^{\circ} \mathbf{C}$} & \multicolumn{2}{c}{$\mathbf{3 7}^{\circ} \mathbf{C}$} \\
\cline { 2 - 5 } & $\ln \boldsymbol{P}$ & $\begin{array}{c}\Delta \mathbf{G}_{\mathbf{s}}{ }^{\circ} \\
\left(\mathbf{k J ~ m o l}^{-1}\right)\end{array}$ & $\ln \boldsymbol{P}$ & $\begin{array}{c}\Delta \mathbf{G}_{s}^{\circ} \\
\left(\mathbf{k J ~ m o l}^{-1} \mathbf{)}\right.\end{array}$ \\
\hline F127 & 0.1245 & -0.3085 & 0.1518 & -0.3912 \\
PF 30 & 0.3321 & -0.8228 & 0.5048 & $-13,010$ \\
PF 50 & 0.7335 & $-18,175$ & 0.6590 & $-16,986$ \\
PF 70 & 0.4498 & $-11,146$ & 0.6386 & $-16,460$ \\
P123 & 0.9565 & $-23,697$ & 0.9507 & $-24,502$ \\
\hline
\end{tabular}


As observed by Kadam et al. ${ }^{[6]}$ in their studies using Pluronics ${ }^{\circledR}$ for solubilisation of carbamazepine, our results show the free energy of solubilisation is negative in all systems, including the PF mixtures, and becomes more negative with the temperature increase. This way the spontaneous griseofulvin solubilisation in the aqueous solutions of these copolymers is manifested by the negative values of $\Delta \mathrm{G}_{S}^{\circ}$. Increasing temperature decreases $\Delta \mathrm{G}_{S}^{\circ}$, what favors its spontaneous solubilisation, since increases the drug/unimer ratio, i.e., the higher number of drug molecules can be accommodated into micelles ${ }^{[6,10]}$.

\section{Conclusions}

These series of block copolymers $\mathrm{E}_{M} \mathrm{P}_{N} \mathrm{E}_{M}$ are frequently used as solubilizing agents for water poorly soluble drugs. In this paper, we have investigated the solubilisation of a hydrophobic drug, griseofulvin, in the binary mixtures of Pluronics ${ }^{\circledR}$ P123 with F127 that self-assemble forming comicelles in dilute aqueous solution.

The CMC values for the mixtures at 25 and $37{ }^{\circ} \mathrm{C}$ were found to be intermediate compared to those of the pure copolymers. The low CMC values of these systems at $37^{\circ} \mathrm{C}$ indicate that their micelles could remain stable even upon dilution in the blood, increasing the circulation time of the drug in the blood. In the studies of particle size, the binary systems showed a single narrow distributionin with a particle size ranging from 20 to $30 \mathrm{~nm}$ at room and body temperature, an advantage for pharmacological applications.

Pluronics ${ }^{\circledR}$ P123 and F127 binary mixtures showed a spontaneous solubilisation of griseolfulvin and could be useful in its pharmacological formulations, since they combine the properties of F127, thermodynamic stability, with the better solubilisation capacities of P123. By a thermodynamic point of view the increase of the temperature from 25 to $37^{\circ} \mathrm{C}$ promotes greater spontaneity and stability to these systems in aqueous solution. Therefore, Pluronic ${ }^{\circledR}$ comicelles can increase drug solubility and stability, making them interesting drug nanocarriers candidates to pharmacological applications.

\section{Acknowledgements}

This work was financially supported by Brazilian Agencies, Conselho Nacional de Desenvolvimento Científico e Tecnológico (CNPq), Fundação Cearense de Apoio ao Desenvolvimento Científico e Tecnológico (FUNCAP) and Coordenação de Aperfeiçoamento de Pessoal de Nível Superior (CAPES).

\section{References}

1. Crothers, M., Zhou, Z., Ricardo, N. M. P. S., Yang, Z., Taboada, P., Chaibundit, C., Attwood, D., \& Booth, C. (2005). Solubilisation in aqueous micellar solutions of block copoly(oxyalkylene)s. International Journal of Pharmaceutics, 293(1-2), 91-100. http:// dx.doi.org/10.1016/j.ijpharm.2004.12.005. PMid:15778048.

2. Mora-Huertas, C. E., Fessi, H., \& Elaissari, A. (2010). Polymerbased nanocapsules for drug delivery. International Journal of Pharmaceutics, 385(1-2), 113-142. http://dx.doi.org/10.1016/j. ijpharm.2009.10.018. PMid:19825408.

3. Xiong, X.-B., Falamarzian, A., Garg, S. M., \& Lavasanifar, A. (2011). Engineering of amphiphilic block copolymers for polymeric micellar drug and gene delivery. Journal of Controlled Release, 155(2), 248-261. http://dx.doi.org/10.1016/j. jconrel.2011.04.028. PMid:21621570.

4. Elluru, M., Ma, H., Hadjiargyrou, M., Hsiao, B. S., \& Chu, B. (2013). Synthesis and characterization of biocompatible hydrogel using Pluronics-based block copolymers. Polymer, 54(8), 2088-2095. http://dx.doi.org/10.1016/j.polymer.2013.02.017.

5. Jindal, N., \& Mehta, S. K. (2015). Nevirapine loaded Poloxamer 407/Pluronic P123 mixed micelles: optimization of formulation and in vitro evaluation. Colloids and Surfaces B: Biointerfaces, 129, 100-106. http://dx.doi.org/10.1016/j.colsurfb.2015.03.030.

6. Kadam, Y., Yerramilli, U., Bahadur, A., \& Bahadur, P. (2011). Micelles from PEO-PPO-PEO block copolymers as nanocontainers for solubilization of a poorly water soluble drug hydrochlorothiazide. Colloids and Surfaces B: Biointerfaces, 83(1), 49-57. http://dx.doi.org/10.1016/j.colsurfb.2010.10.041. PMid:21123038.

7. Zhang, W., Shi, Y., Chen, Y., Ye, J., Sha, X., \& Fang, X. (2011). Multifunctional Pluronic P123/F127 mixed polymeric micelles loaded with paclitaxel for the treatment of multidrug resistant tumors. Biomaterials, 32(11), 2894-2906. http://dx.doi. org/10.1016/j.biomaterials.2010.12.039. PMid:21256584.

8. Lee, E. S., Oh, Y. T., Youn, Y. S., Nam, M., Park, B., Yun, J., Kim, J. H., Song, H.-T., \& Oh, K. T. (2011). Binary mixing of micelles using Pluronics for a nano-sized drug delivery system. Colloids and Surfaces B: Biointerfaces, 82(1), 190-195. http:// dx.doi.org/10.1016/j.colsurfb.2010.08.033. PMid:20850281.

9. Zhang, M., Djabourov, M., Bourgaux, C., \& Bouchemal, K. (2013). Nanostructured fluids from pluronic ${ }^{\circledR}$ mixtures. International Journal of Pharmaceutics, 454(2), 599-610. http:// dx.doi.org/10.1016/j.ijpharm.2013.01.043. PMid:23370436.

10. Alexandridis, P., Holzwarth, J. F., \& Hatton, T. A. (1994). Micellization of Poly(ethylene oxide)-Poly(propylene oxide)Poly(ethylene oxide) triblock copolymers in aqueous solutions: thermodynamics of copolymer association. Macromolecules, 27(9), 2414-2425. http://dx.doi.org/10.1021/ma00087a009.

11. Chaibundit, C., Ricardo, N. M. P. S., Costa, F. D. M. L. L., Yeates, S. G., \& Booth, C. (2007). Micellization and gelation of mixed copolymers P123 and F127 in aqueous solution. Langmuir, 23(18), 9229-9236. http://dx.doi.org/10.1021/ la701157j. PMid:17676776.

12. Wei, Z., Hao, J., Yuan, S., Li, Y., Juan, W., Sha, X., \& Fang, X. (2009). Paclitaxel-loaded Pluronic P123/F127 mixed polymeric micelles: formulation, optimization and in vitro characterization. International Journal of Pharmaceutics, 376(12), 176-185. http://dx.doi.org/10.1016/j.ijpharm.2009.04.030. PMid:19409463.

13. Oh, K. T., Bronich, T. K., \& Kabanov, A. V. (2004). Micellar formulations for drug delivery based on mixtures of hydrophobic and hydrophilic Pluronic ${ }^{\circledR}$ block copolymers. Journal of Controlled Release, 94(2-3), 411-422. http://dx.doi.org/10.1016/j. jconrel.2003.10.018. PMid:14744491.

14. Rekatas, C. J., Mai, S.-M., Crothers, M., Quinn, M., Collett, J. H., Attwood, D., Heatley, F., Martini, L., \& Booth, C. (2001). The effect of hydrophobe chemical structure and chain length on the solubilization of griseofulvin in aqueous micellar solutions of block copoly(oxyalkylene)s. Physical Chemistry Chemical Physics, 3(21), 4769-4773. http://dx.doi.org/10.1039/ b107073h.

15. Aliabadi, H. M., \& Lavasanifar, A. (2006). Polymeric micelles for drug delivery. Expert Opinion on Drug Delivery, 3(1), 139-162. http://dx.doi.org/10.1517/17425247.3.1.139. PMid:16370946.

16. Ribeiro, M. E. N. P., Vieira, Í. G. P., Cavalcante, I. M., Ricardo, N. M. P. S., Attwood, D., Yeates, S. G., \& Booth, C. (2009). Solubilisation of griseofulvin, quercetin and rutin in micellar formulations of triblock copolymers E62P39E62 and 
E137S18E137. International Journal of Pharmaceutics, 378(1-2), 211-214. http://dx.doi.org/10.1016/j.ijpharm.2009.05.047. PMid:19501147.

17. Zhong, N., Chen, H., Zhao, Q., Wang, H., Yu, X., Eaves, A. M., Sheng, W., Miao, J., Cui, F., \& Wang, J. (2010). Effects of griseofulvin on apoptosis through caspase-3- and caspase-9dependent pathways in K562 leukemia cells: An in vitro study. Current Therapeutic Research, Clinical and Experimental, 71(6), 384-397. http://dx.doi.org/10.1016/S0011-393X(10)80004-9. PMid:24688157.

18. Attwood, D., Booth, C., Yeates, S. G., Chaibundit, C., \& Ricardo, N. M. P. S. (2007). Block copolymers for drug solubilisation: Relative hydrophobicities of polyether and polyester micelle-core-forming blocks. International Journal of Pharmaceutics, 345(1-2), 35-41.http://dx.doi.org/10.1016/j. ijpharm.2007.07.039. PMid:17869036.

19. Kulthe, S. S., Inamdar, N. N., Choudhari, Y. M., Shirolikar, S. M., Borde, L. C., \& Mourya, V. K. (2011). Mixed micelle formation with hydrophobic and hydrophilic Pluronic block copolymers: Implications for controlled and targeted drug delivery. Colloids and Surfaces B: Biointerfaces, 88(2), 691-696. http://dx.doi.org/10.1016/j.colsurfb.2011.08.002. PMid:21862296.

20. Tadros, T. F. (2005). Applied Surfactants: principles and applications. Weinheim: WILEY-VCH.
21. Kadam, Y., Yerramilli, U., \& Bahadur, A. (2009). Solubilization of poorly water-soluble drug carbamezapine in Pluronic ${ }^{\circledR}$ micelles: effect of molecular characteristics, temperature and added salt on the solubilizing capacity. Colloids and Surfaces B: Biointerfaces, 72(1), 141-147. http://dx.doi.org/10.1016/j. colsurfb.2009.03.027. PMid:19403275.

22. Attwood, D., \& Booth, C. (2007). Solubilization of a poorly soluble aromatic drug by micellar solutions of amphiphilic block copoly(oxyalkylene)s. In T. F. Tadros (Ed.), Colloid stability and application in pharmacy (pp. 61-78). Weinheim: Wiley-VCH.

23. Attia, A. B. E., Ong, Z. Y., Hedrick, J. L., Lee, P. P., Ee, P. L. R., Hammond, P. T., \& Yang, Y.-Y. (2011). Mixed micelles self-assembled from block copolymers for drug delivery. Current Opinion in Colloid \& Interface Science, 16(3), 182194. http://dx.doi.org/10.1016/j.cocis.2010.10.003.

24. Ribeiro, M. E. N. P., Moura, C. L., Vieira, M. G. S., Gramosa, N. V., Chaibundit, C., Mattos, M. C., Attwood, D., Yeates, S. G., Nixon, S. K., \& Ricardo, N. M. P. S. (2012). Solubilisation capacity of Brij surfactants. International Journal of Pharmaceutics, 436(1-2), 631-635. http://dx.doi.org/10.1016/j. ijpharm.2012.07.032. PMid:22842626.

Received: July 08, 2014 Revised: Mar. 24, 2015 Accepted: Apr. 22, 2015 